Anuario Latinoamericano Ciencias Políticas

y Relaciones Internacionales

vol. 9, 2020

pp. $37-51$

\section{La dinámica de las relaciones diplomáticas entre Venezuela y los Estados Unidos durante el gobierno del general Isaías Medina Angarita (1941-1945)}

DOI: $10.17951 /$ al.2020.9.37-51

\section{The Dynamics of Diplomatic Relations Between Venezuela and the United States During the Government of General Isaias Medina Angarita (1941-1945)}

\author{
Luis Manuel Marcano Salazar* \\ FACULTAD DE DERECHO Y CIENCIAS SOCIALES \\ UNIVERSIDAD SEK \\ SANTIAGO, CHILE \\ $\triangle$ luis.marcano@zonavirtual.uisek.cl \\ https://orcid.org/0000-0003-0470-5764/
}

\title{
RESUMEN
}

La presente investigación analiza las relaciones entre los Estados Unidos de América $y$ Venezuela en tiempos del gobierno democrático del general Isaías Medina Angarita. Partimos de la hipótesis que considera que las relaciones entre Venezuela y los Estados Unidos en función del reconocimiento diplomático y de la consecuente aceptación política estuvieron condicionadas por factores de orden económico y político derivado por el interés estadounidense en el petróleo venezolano y por la necesidad de garantizar la estabilidad de los mercados comerciales, inclusive durante la Segunda Guerra Mundial.

PALABRAS ClaVe: Venezuela, Estados Unidos de América, petróleo, Segunda Guerra Mundial, Organización de Naciones Unidas.

\section{ABSTRACT}

This research paper analyzes the relations between the United States of America and Venezuela in times of the democratic government of General Isaías Medina Angarita. We start from the hypothesis that the relations between Venezuela and the United

* Doctor en Historia por la Universidad Católica Andrés Bello, Caracas, Venezuela. Académico-investigador. 
Dossier América Latina: Venezuela
States, based on diplomatic recognition and the consequent political acceptance, were conditioned by economic and political factors derived from the US interest in Venezuelan petroleum and the need to guarantee stability of commercial markets, even during World War II.

KEYWORDS: Venezuela, United States of America, petroleum, World War II, United Nations Organization.

\section{Introducción}

El 5 de mayo de 1941, el mismo día que el emperador de Abisinia (Etiopía), Haile Selassie, regresa a Addis-Abeba (Argyle, 1991, p. 63), en medio de la cruenta realidad de la Guerra Mundial que azotaba a Europa, África y Asia, Isaías Medina Angarita asume el cargo como presidente de la República. Son días oscuros para la humanidad que luchaba por el rescate y supervivencia de las democracias amenazadas por las ambiciones desmedidas de las autocracias europeas y asiática. Un día antes, Hitler pronosticaba en el Reichstag que la Alemania nacional socialista duraría mil años. La situación mundial contrastaba con lo que ocurría en el Congreso de Venezuela durante esa mañana de mayo, bajo las miradas atentas del Departamento de Estado.

Ya desde el primero de mayo, cuando el secretario de Guerra de los Estados Unidos de Norte América, Henry L. Stimson, envía a la embajada americana en Caracas, particularmente a la agregaduría militar estadounidense, una efusiva felicitación al general Medina por haber sido electo presidente de Venezuela, se puede interpretar el nivel de jerarquía que el gobierno estadounidense otorgó al fuero militar venezolano y el interés particular sobre las relaciones bilaterales.

El gobierno democrático que se inauguró aquel 5 de mayo de $1941 \mathrm{selec}$ cionó a uno de los diplomáticos que había tenido protagonismo en la Liga de Naciones y que sabría testificar sobre sus aciertos y errores. Caracciolo Parra Pérez, Doctor en Derecho por la Universidad de Los Andes, inicia su largo periplo diplomático en 1913 como miembro de la reciente estructurada Legación de Venezuela en París (ACMRE, 1913), siendo ascendido un año después a secretario (ACMRE, 1914). Descollante de virtudes por una larga actividad diplomática, que le lleva a Italia en 1926 como ministro plenipotenciario en duros momentos para la sociedad italiana dominada por la autocracia de Benito Mussolini (ACMRE, 1926), habría de sustituir a su amigo mentor Gil Borges al frente de la diplomacia venezolana.

Desde las postrimerías de la campaña presidencial, la mirada detenida del gobierno norteamericano tenía en buena opinión la figura del general Medina Angarita. Así lo testifica la comunicación producida por la embajada estadounidense en Caracas al Departamento de Estado cuando se considera al 
virtual presidente como “...un hombre con capacidad y además respetado en las filas de las fuerzas armadas venezolanas” (NARA, 1940) ${ }^{1}$.

Sin embargo, en la misma comunicación Corrigan advierte sobre la desconfianza de la que gozaba en Venezuela Medina Angarita por ser considerado por sectores de la sociedad como la continuación y renovación del gomecismo, por haber sido secretario privado del presidente Eleazar López Contreras y su hombre de confianza. Durante toda la etapa electoral que culminó con la elección presidencial por el Congreso, los Estados Unidos permanecieron atentos a los acontecimientos a través de la mesurada observación de su representante, el embajador Corrigan. En tales circunstancias, dos días después de las elecciones, el 30 de abril de 1941, Corrigan advertirá al Departamento de Estado sobre la poca popularidad del nuevo presidente al comparar el número de personas que asistió a su proclamación con la multitud que acostumbraba a acompañar al general López Contreras en sus mensajes al Congreso (NARA, 1941)2.

Nuestro objetivo será aproximarnos a esa realidad diplomática a partir de fuentes primarias recabadas en los Archivos Nacionales de Washington D.C. y en los archivos de la cancillería venezolana y del palacio presidencial, e intentar dar respuesta a dos preguntas fundamentales: ¿estuvo la política exterior del gobierno de los Estados Unidos hacia Venezuela en el período1941-1945 condicionada por el factor petrolero únicamente?, y ¿fue fundamental el tema petrolero para la consolidación de un entendimiento mutuo? Las páginas que siguen ilustrarán a los académicos, investigadores y personas interesadas sobre ese proceso de tensiones y distensiones, de marcados intereses geopolíticos y energéticos y grandes coincidencias en una época de la guerra y la incertidumbre. El lector podrá llegar a sus propias conclusiones en la revisión de este trabajo que se constituye en una apasionante reconstrucción histórico-documental.

\section{El medinismo y la Segunda Guerra Mundial: de la mano de los Estados Unidos}

Desde 1940, el Departamento de Estado norteamericano mostraba preocupación por las actividades nacionalsocialistas en Venezuela y Colombia. El encargado de negocios a.i. de la embajada de los Estados Unidos de América, Winthrop P. Scott, envió un amplio informe al Departamento de Estado mediante el cual identificó plenamente a los dirigentes nazis en Caracas:

1 Comunicación emitida por el embajador de los Estados Unidos de América en Caracas, Frank Corrigan, de fecha 30 de abril de 1940, dirigida al subsecretario de Estado norteamericano, Sumner Welles, mediante la cual opina que parte de la sociedad venezolana considera a Medina Angarita como un "Gómez Joven” o la continuidad del gomecismo.

2 Comunicación emitida por el embajador de los Estados Unidos de América en Caracas, Corrigan, de fecha 30 de abril de 1941, dirigida al Secretario de Estado norteamericano mediante la cual hace una comparación política entre el carisma del general Medina Angarita y la afabilidad de López Contreras.
La dinámica de las relaciones diplomáticas entre Venezuela y los Estados Unidos durante el gobierno del general Isaías Medina Angarita (1941-1945)

Luis Manuel Marcano Salazar 
Dossier América Latina: Venezuela ...funcionarios del partido nazi en Caracas, jefe del partido nazi en Venezuela: Margeril, Arnold, anteriormente gerente de la empresa Bayer (...) Gestapo: Gathmann, venezolano, copropietario de una de las principales joyerías. Fogoso nazi y donante de una suma considerable que se dice en trescientos mil bolivares al partido. Actualmente sujeto a vigilancia por las autoridades venezolanas. (Archivo Diplomático FUNRES, 1940) ${ }^{3}$

La comunicación es expresión del trabajo detallado de la inteligencia americana y de la importancia de las actividades nazis en Venezuela. En efecto, inclusive extrabajadores de las compañías petroleras, como el ingeniero Briggs, funcionario de la Standard Oil Company, fungieron como informantes de las actividades nacionalsocialistas alrededor de los campos petroleros (Archivo Diplomático FUNRES, 1945)4. Llama la atención que Briggs calificó la conducta de los alemanes en Venezuela como de amistosa, “...tratan de hablar español y hacer amistad con los nativos, por lo cual considero que facilitarían alguna invasión contra el Canal de Panamá..." (Archivo Diplomático FUNRES, 1945). Es reiterativa la declaración de Briggs cuando informa sobre el llamado del Dog Tag, que no es otra cosa que la activación de oficiales alemanes encubiertos en Venezuela para generar sabotajes contra las refinerías petroleras en caso de que se haga necesario (Archivo Diplomático FUNRES, 1945).

Como bien lo expresa el propio canciller Parra Pérez en la Introducción a la Memoria del Ministerio de Relaciones Exteriores de 1941, para cuando Medina asume la dirección del país, la guerra de Europa ya había cobrado muchas vidas por el desafuero hitleriano de avanzar contra pueblos y ciudades libres (MRE, Memoria, 1941). La ocupación alemana en Francia, desde junio de 1940, generó que el Departamento de Estado observara América Latina, el petróleo venezolano y las actividades de alemanes, italianos y japoneses. En efecto, sin existir un estado de guerra con el imperio del Japón, ya los Estados Unidos habían desplegado un bloqueo económico contra el militarismo japonés por sus incursiones en Manchuria, asunto que se complicaría en el Pacífico.

La entereza del presidente Medina frente a los acontecimientos europeos se demostró en la posición asumida por el gobierno de colaborar ampliamente con los Estados Unidos en la defensa continental sin que ello implicara el menoscabo de la soberanía venezolana. Así, en una larga nota confidencial sobre el tema de la defensa nacional, de fecha 18 de junio de 1941, firmada

3 Comunicación signada por el encargado de negocios a. i. de la embajada de los Estados Unidos en Caracas, de fecha 17 de mayo de 1940, mediante la cual informa al Departamento de Estado sobre las actividades de miembros del partido nazi en Venezuela.

${ }_{4}$ Comunicación signada por el coronel Henri A. Lucbbamann, agregado militar de la embajada de los Estados Unidos en Caracas, de fecha 21 de marzo de 1945, mediante la cual informa al Departamento de Estado sobre las actividades de presuntos nazis, alemanes en Venezuela cerca de las refinerías petroleras, dueños de hoteles, y terratenientes. Se presumía que esperaban el Dog Tag, o activación para producir daños (traducción libre del autor). 
por el canciller Parra Pérez, se exponen los principios de la política exterior en tiempos de guerra: "La primera providencia sería reforzar con la colaboración norteamericana nuestro servicio de informaciones, sobre todo en materia de política militar y naval, conforme se previó en las conversaciones citadas" (ACMRE, 1941a) $)^{5}$.

Estaba claro para el presidente y su canciller que el tema de la soberanía nacional formaba parte de un interés vital sobre el cual no cabía ningún tipo de negociación a pesar del conflicto mundial que se estaba desarrollando en el sistema internacional. Comprendemos que el interés de defender el continente estaba supeditado al cumplimento de normas internacionales y morales que Venezuela debía observar, plasmadas en las conferencias panamericanas que invocaron la necesidad de la paz hemisférica (MRE, 1928-1954). En este sentido, la cancillería venezolana se mantuvo ocupada de dar seguimiento tanto a los acontecimientos en Europa como a la reacción de las naciones suramericanas frente a la eventual participación de los Estados Unidos en la guerra (MRE, Dirección General Brasil, s.f.) ${ }^{6}$. Véase que la postura venezolana de inmediato era de prudencia, lo que nos hace entender que cualquier posición internacional estaría inmersa en una política de bloque regional y orientada por el cumplimiento de los compromisos regionales adquiridos (ACMRE, 1941b $)^{7}$. Una fluida e intensa comunicación diplomática entre las naciones latinoamericanas se desplegó luego del 7 de diciembre de 1941 cuando la flota imperial japonesa atacara la base naval estadounidense en Hawái, Pearl Harbor. Y es que el aludido compromiso contraído por Venezuela en las conferencias panamericanas invocaba los principios de integridad y solidaridad de América, razón por la cual todas las naciones suramericanas sentían la agresión sufrida por los Estados Unidos como propia (ACMRE, 1941c) ${ }^{8}$.

El martes 9 de diciembre, dos días después del fatídico domingo en Hawái, la reacción del Departamento de Estado no se hizo esperar en lo relativo a la vigilancia de actividades hostiles en Venezuela. El cónsul americano en Maracaibo remitió al presidente Medina una copia del telegrama enviado por el embajador de los Estados Unidos, Corrigan, a todas las secciones consulares

5 Nota confidencial del Doctor Parra Pérez sobre la defensa nacional. Precauciones que debe tomar Venezuela ante una guerra abierta entre los Estados Unidos con Alemania e Italia.

6 Nota de la embajada de Venezuela en Río de Janeiro. El Ministro de Relaciones Exteriores desea información constante de la reacción de los círculos oficiales del Brasil sobre el Discurso del presidente Roosevelt y acerca de la actitud de algunos países si los Estados Unidos entran en el conflicto.

7 Nota de la Embajada de Venezuela en Bogotá, Colombia, mediante la cual se ratifica a Colombia que la nación está dispuesta a cumplir los compromisos contraídos en las conferencias panamericanas. Caracas, 8 de diciembre de 1941.

8 Nota del canciller Caracciolo Parra Pérez al Ministro de Estado José Manuel Cortina de Cuba, mediante la cual Venezuela manifiesta que, ante la agresión japonesa a posesiones de los Estados Unidos, el país está dispuesto a cumplir los compromisos contraídos en las conferencias de Lima, Panamá y La Habana en sostener los principios de integridad y solidaridad de América.
La dinámica de las relaciones diplomáticas entre Venezuela y los Estados Unidos durante el gobierno del general Isaías Medina Angarita (1941-1945)

Luis Manuel Marcano Salazar 
Dossier América Latina: Venezuela

americanas en Venezuela que expresaba el imperativo de interrumpir cualquier actividad de súbditos japoneses residenciados en Venezuela:

Sr General Isaías Medina A.-

Caracas a Maracaibo 9 de diciembre. Cónsul Americano. -

(...) se le solicitó que se colocara de inmediato en comunicación con la autoridad ante la cual está acreditado en relación con las actividades japonesas en el hemisferio occidental. Se le solicitó inmediatamente que llamara la atención de las autoridades respectivas del gobierno ante el cual está usted acreditado para determinar las medidas que han sido tomadas por el gobierno que afecte las actividades económicas japonesas en ese país.

Su amigo J.M. Gragirman (Archivo de Miraflores, 1941) ${ }^{9}$

No era distante el gobierno de las terribles repercusiones que traería la invasión japonesa. Paralelamente, el mismo día de producida la comunicación, el presidente Isaías Medina Angarita se dirigía a la nación para condenar de la manera más categórica la flagrante violación del derecho internacional y de la paz mundial:

La serie de graves sucesos internacionales que se vienen sucediendo con pavorosa extensión e intensidad acaba de culminar con la agresión llevada a efecto contra los Estados Unidos de América por el Imperio del Japón; agresión que Venezuela condena en nombre de postulados que han sido siempre suyos, en virtud de pactos solemnes que la hacen solidaria de todas y cada una de las naciones del continente, y que la llevan a colocarse con viva sinceridad, al lado de los Estados Unidos. (Archivo de Miraflores, 1941b) ${ }^{10}$

De inmediato, por órgano de la cancillería venezolana se remite una circular a las embajadas y legaciones de Venezuela relativa a la necesidad de enfatizar solidaridad de Venezuela con los Estados Unidos y el Continente:

Ante los últimos sucesos que han agravado la situación internacional, el Presidente de la República, en Consejo de Ministros, resolvió declarar que Venezuela cumplirá integramente las obligaciones contraídas con los Estados Unidos de América y con todas las naciones del Continente, en virtud de los Convenios Interamericanos y animada del espiritu de solidaridad continental que históricamente ha guiado su política exterior.

El gobierno Nacional está seguro de que el pueblo venezolano confrontará la situación con serenidad y que su conducta contribuirá a facilitar la

9 Telegrama enviado por el cónsul de Maracaibo al presidente Isaías Medina Angarita relativo a la paralización inmediata de las actividades económicas japonesas en el territorio nacional.

${ }_{10}$ Alocución con motivo de la agresión contra los Estados Unidos de América por el Imperio del Japón. 
solución de los arduos problemas que hoy se plantean a la República. Sírvase comunicar Cónsules su jurisdicción. Parra Pérez (ACMRE, 1941d)

Los días que siguieron al 7 de diciembre de 1941 fueron intensos en la diplomacia venezolana para ratificar la solidaridad del gobierno del presidente Medina con la causa de la libertad. El 10 de diciembre, la cancillería envía un radiograma a la embajada de Venezuela en los Estados Unidos:

Embavenez-Washington

Referencia su radiograma 167 remitole a los despachos de este Ministerio números 376 y circulares fechas 8 y 10 corriente que indican con entera claridad la posición asumida por Venezuela ante agresión japonesa. Usted puede basarse en dichos despachos para hacer las declaraciones que juzgue necesarias.

Presidente de la República telegrafió anoche al presidente Roosevelt y yo envié hoy radiograma personal al señor Cordel Hull. (ACMRE, 1941e)

A pesar de la solidaridad de Venezuela con los Estados Unidos, plasmada en diversidad de notas diplomáticas, sorprende el contenido de la nota confidencial que dirigiera Parra Pérez a la legación de Venezuela en Roma en donde acota: "para su exclusiva y confidencial información notifícole que prevéase posible ruptura relaciones esa nación..." (ACMRE, 1941f). Y es que la reacción del gobierno nacional de romper relaciones con las potencias del Eje esperaba la reunión de Río de Janeiro mediante la cual la ruptura sería el producto de una decisión colectiva de todas las naciones latinoamericanas. A esto se sumaba la preocupación de la cancillería en evacuar a los nacionales que aún se encontraban en el teatro de guerra europeo (ACMRE, 1941g) ${ }^{11}$. En efecto, Parra Pérez enfatiza en la nota la posición del gobierno respecto a la inminente ruptura con las potencias del Eje:

La ruptura decidida en conjunto sería sin duda la más importante resolución que podría adoptar la conferencia y revestiría de esa forma mayor significación moral y política. Por otra parte, la ruptura inmediata requeriría la aplicación de medidas y precauciones que sólo están en curso actual, relacionadas con la politica interna del país. (ACMRE, 1941g)

Finalmente, el 30 de diciembre de 1941, 23 días después de la invasión japonesa, el canciller Parra Pérez remitió a la embajada de Venezuela en Washington el siguiente comunicado:

La ruptura diplomática expondrá aún más a Venezuela a posibles ataques de parte de los enemigos de Estados Unidos y reclamará mayores precauciones

${ }^{11}$ Nota de la cancillería firmada por el canciller Parra Pérez mediante la cual Venezuela esperaría las decisiones de la Conferencia de Río de Janeiro.
La dinámica de las relaciones diplomáticas entre Venezuela y los Estados Unidos durante el gobierno del general Isaías Medina Angarita (1941-1945)

Luis Manuel Marcano Salazar 
Dossier

América Latina:

Venezuela

defensivas, por cuyo motivo el país tiene necesidad de obtener armamento a la mayor brevedad posible de coordinar las medidas indispensables de acuerdo con mis radiogramas números 399 y 439. (ACMRE, 1941h)

La guerra llega a Venezuela de una manera colateral: los ciudadanos venezolanos en Europa y la solidaridad con los Estados Unidos de Norteamérica. Una incansable campaña de repatriación de venezolanos en Europa desplegó la cancillería por órgano de la legación de Venezuela en Madrid (ACMRE, 1941i) ${ }^{12}$, al tiempo de incautar navíos-cargueros italianos y alemanes en puertos venezolanos (ACMRE, 1941j).

Posterior a la ruptura con las potencias del Eje, el gobierno se fijó como objetivo la defensa de las costas, situación que se vinculó con la presencia militar norteamericana en Curazao y Aruba que temían el ataque de submarinos alemanes que circundaban el océano Atlántico, acechando las posesiones holandesas en el Caribe con importantes suministros petroleros (ACMRE, 1941k) ${ }^{13}$.

Como consecuencia de ello, ocurrieron un conjunto de tensiones y distensiones entre Holanda y Venezuela por la insistencia del gobierno venezolano de participar en la defensa de las islas holandesas. Los Estados Unidos mediaron frente a la posición adversa de Holanda y, finalmente, se suscribió entre ambas naciones un pacto de asistencia militar suplementario al acuerdo firmado entre Holanda y los Estados Unidos (ACMRE, 1941k).

Las acciones de guerra no se hicieron esperar. El 15 de febrero de 1942, un buque de bandera venezolana fue torpedeado por un submarino alemán. De inmediato, el canciller Parra Pérez inició una campaña diplomática frente a los Estados Unidos para solicitar garantía de la defensa del Caribe con el temor de que situaciones similares establecieran un bloqueo de facto (ACMRE, 1942a $)^{14}$. Así en comunicación firmada por el canciller Parra Pérez en marzo de 1942, solicitó el apoyo del Comando Unido de las Fuerzas Navales del Caribe de los Estados Unidos de Norteamérica para realizar la escolta de buques:

Gobierno cree necesario que buques-cisternas bandera venezolana que transportan petróleo de Maracaibo a las Piedras, Aruba y Curazao y los que salen de Puerto La Cruz para Estados Unidos formen parte de convoyes barcos petroleros ingleses y holandeses escoltados (punto) Agregado naval Embajada Americana informó que para que barcos venezolanos puedan navegar en convoyes con éstos es indispensable autorización del Comando Unido

12 Radiograma mediante el cual la Legación de Venezuela en Madrid gestionará ante el gobierno español el libre tránsito en España, garantizando la Legación pagar el pasaje a repatriados.

13 Nota de la cancillería que comunica al embajador Escalante en Washington, solicitar al gobierno estadounidense solidaridad continental en el caso de protección de Curazao, Aruba y Bonaire.

14 Nota de la cancillería que comunica al embajador Escalante la presencia de submarinos alemanes en el Caribe y el hundimiento del vapor Monagas de bandera venezolana. 
Fuerzas Navales del Caribe (punto) Sírvase tratar urgentemente asunto con Departamento de Estado y comunicarme el resultado. (ACMRE, 1942b) ${ }^{15}$

Luego del hundimiento del Vapor Monagas se produjo el pacto tripartito de defensa mutua Colombia-Venezuela-Estados Unidos a fin de evitar nuevas incursiones de submarinos alemanes en aguas del Caribe:

\section{Embajada de Venezuela en Colombia}

Actualmente se llevan aquí conversaciones con oficiales americanos destinados a coordinar medidas defensivas. Se les ha ofrecido libre tránsito en puertos y aeródromos sin estacionamiento navíos ni aviones [...] Se ha ratificado a los comandantes americanos que Venezuela asegurará su propia defensa y que de esta forma contribuirá a la del Continente.

Parra Pérez (ACMRE, 1942c) ${ }^{16}$

Mientras la guerra se intensificaba en las campañas del Pacífico, las materias primas eran necesarias para suplir a los infantes de marina, generando la escasez que fue incrementándose proporcionalmente con el aumento de las hostilidades.

En efecto, parte del problema del desabastecimiento se produjo como consecuencia de las denominadas "listas negras" realizadas por agentes comerciales estadounidenses y británicos sobre las casas venezolanas que mantenían relaciones con comercios extranjeros vinculados con las potencias del Eje. Precisamente este tema desarrollaría otra de las tendencias proclives a ratificar el reconocimiento político de los Estados Unidos a Venezuela en tiempos de profunda crisis. Se trató de presiones, acomodos y reacomodos sobre posturas políticas y económicas. En este sentido, el canciller Parra Pérez manifestó su preocupación a las embajadas de Venezuela en América del Sur:

\section{Embavenez- Río de Janeiro.}

DG. 56. CIRCULAR. Estrictamente confidencial. Situaciones listas negras en Venezuela es siguiente: Agentes comerciales Estados Unidos y Gran Bretaña amenazan casas venezolanas con incluirlas dichas listas si comercian con firmas ya incluidas en ellas. Actualmente existe aquí Comisión que funciona conjuntamente con representantes americanos designados al efecto y cuyas finalidades son: Primero. Examinar si hay motivos justificados para mantener o incluir una forma en la lista y en caso negativo procurar excluirla. Segundo. En caso afirmativo y si se trata de empresa vital importancia, recomendar al gobierno adopción medidas que permitan funcionamiento

${ }^{15}$ Nota de la cancillería mediante la cual se solicita la asistencia de las Fuerzas Navales Norteamericanas para el transporte de petróleo venezolano.

${ }^{16}$ Nota de la cancillería mediante la cual se informa sobre conversaciones con oficiales americanos destinados a coordinar medidas defensivas.
La dinámica de las relaciones diplomáticas entre Venezuela y los Estados Unidos durante el gobierno del general Isaías Medina Angarita (1941-1945)

Luis Manuel Marcano Salazar 
Dossier América Latina:

Venezuela esa empresa y realicen mismo tiempo fines seguridad que persigue Gobierno americano con listas negras.

Parra Pérez

Quito 20 de enero de 1943 (ACMRE, 1943a)

Los grandes temas comerciales formaban parte de la agenda venezolana de política exterior, paralelamente con la necesidad de resguardar la soberanía tanto del ataque de las potencias del Eje como la incursión militar norteamericana en suelo venezolano.

El primer trimestre de 1943 significó un punto álgido en la cruenta guerra que se libraba en el frente oriental. El 2 de febrero termina la campaña de Stalingrado que se cobra la vida de " 110.500 alemanes muertos, 50.000 heridos aproximadamente y 750.00 soviéticos y 250.000 civiles” (Argyle, 1991, p. 121).

Esta situación sumada a las intensas batallas desde Guadalcanal hasta el mar de Bismark (Argyle, 1991, p. 120) acrecentarán el tema del desabastecimiento, lo que generará que las "listas negras" que impactaban desfavorablemente la economía interna atentaran contra el estómago de los venezolanos. En este sentido, el presidente Medina, advenido del peligro sobre el tema de las "listas negras", dictó decreto para estudiar cada caso. Por su parte, el canciller Parra Pérez remitió a la embajada de Venezuela en Washington el siguiente comunicado:

DG.667. ... En cuenta a casos como Blohm y Frey, sírvase solicitar Departamento de Estado envío brevedad posible perito ofrecido a ministro Rojas, para estudie personalmente con Ministerio de Hacienda la solución que deba aceptarse y que gobierno desea rápida y definitiva.

Corren rumores inminentes inclusión telares Maracay en lista negra. Sírvase indicar Departamento de Estado graves consecuencias tendría esta medida, comunicándole al mismo tiempo que telares ha recibido orden abstenerse vender firmas que figuran lista negra, en espera arreglos arriba señalados.

Parra Pérez (ACMRE, 1943b)

A pesar de estas fricciones diplomático-comerciales, Venezuela se mantenía solidaria con las aspiraciones de los aliados en la Guerra Mundial. Así lo supo ratificar el canciller Parra Pérez el 13 de febrero de 1943, cuando dirigió una comunicación al embajador de los Estados Unidos de Norteamérica, Frank Corrigan, reiterando la adhesión del Gobierno venezolano a los principios contenidos en la Carta del Atlántico:

Señor Embajador:

[...]En la Reunión Consultiva de Río de Janeiro, el Gobierno de Venezuela manifestó su completo acuerdo con los mencionados principios cuando, 
en unión de los gobiernos de Estados Unidos de América, de Bolivia, Costa Rica, Cuba y México, presentó proyecto de resolución en el cual las naciones americanas daban su plena adhesión y apoyo a la Carta referida.

$$
\text { C. Parra Pérez (MRE. Memoria, 1943, pp. 15-16) }{ }^{17}
$$

Esta misiva se veía necesaria, dados los desencuentros ocurridos como consecuencia de las "listas negras", en momentos en los cuales la solidaridad venezolana no podía estar en entredicho, por su condición de país petrolero.

Efectivamente, los principios de la Carta del Atlántico regirían no sólo la política exterior de Venezuela en tiempos de la Guerra Mundial, sino que se constituirá en el gran tema de la paz y la coexistencia pacífica de los Estados en el futuro. En este sentido, Venezuela asumirá el compromiso, aun cuando la guerra siguiera su curso, de participar en la Comisión para el Estudio de las Cuestiones de la Postguerra (MRE, 1944, pp. 83-84). Asuntos como el socorro y la rehabilitación serán temas asumidos por la diplomacia venezolana para su estudio (MRE,1944, pp. 83-84).

La aproximación entre Venezuela y los Estados Unidos llegaría pronto a un nivel inédito. En febrero de 1944, el presidente Medina respondió a la invitación del presidente estadounidense Franklin Delano Roosevelt. Era la primera vez que un presidente venezolano en ejercicio de sus funciones visitaba los Estados Unidos. Cordel Hull, en su carácter de Secretario de Estado norteamericano y presidente de la Unión Panamericana le recibe en ocasión de la sesión celebrada por el Consejo Directivo en su honor.

Frente al Congreso de los Estados Unidos de América Medina identificará los principios de las relaciones entre los dos pueblos:

Yo os traigo y comparto el saludo de un pueblo que entiende y comparte vuestras aspiraciones que ha luchado por ellas y que está dispuesto a sostener ideales y principios que nos son comunes. (...) Venezuela es un país libre, aspiramos en vivir en un mundo regido por la justicia y por el Derecho ofreciendo a ustedes mutua ayuda, mutuo respeto y mutua confianza, ni queremos ser engañados ni engañamos, con buena fe entera servimos la causa de las democracias y la justicia que sabemos es pues también la vuestra, nuestro petróleo afortunadamente abundante, ha ido y seguirá yendo hasta los campos de batalla al lado de las democracias. (Bolívar Films, 32-34)

De la misma manera cordial que le caracterizó como líder de la diplomacia venezolana, Medina aceptó la invitación que le hiciera la Cámara de Comercio de Nueva York en donde sintetizó los lineamientos de la política económica del gobierno:

${ }_{17}$ Nota del canciller Parra Pérez al embajador Frank Corrigan de los Estados Unidos de América reiterando la adhesión de Venezuela a los principios contenidos en la Carta del Atlántico.
La dinámica de las relaciones diplomáticas entre Venezuela y los Estados Unidos durante el gobierno del general Isaías Medina Angarita (1941-1945)

Luis Manuel Marcano Salazar 


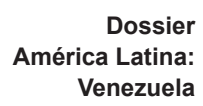

Venezuela
Lo que hemos hecho con el petróleo debe ser de ejemplo a los hombres de empresa que deseen cooperar con su iniciativa al desarrollo material de Venezuela, y deben saber que no pueden contar con privilegios ni favores pero deben saber igualmente que las empresas que inicien pueden contar con un tratamiento equitativo y la protección de un régimen democrático estable y con la buena voluntad de una nación que sabe corresponder con quienes también de buena voluntad vienen a cooperar con ella para su progreso. (Bolívar Films, 32-34)

Ambos discursos frente a la jerarquía política y económica de los Estados Unidos giraron alrededor de dos objetivos: asegurar unas relaciones justas, equitativas y solidarias y preservar el derecho del gobierno venezolano a garantizar su soberanía política y económica. Después de los acontecimientos europeos que trajeron como protagonista a los aliados, vencedores en la muralla del Atlántico que cubría las playas de Normandía el 6 de junio de 1944, y la posterior liberación de Bélgica y Francia, el panorama de la guerra se hacía prometedor.

\section{Conclusiones}

El apego de la política exterior de Venezuela a la estadounidense y a sus aliados durante el conflicto mundial fue tan estrecho que cuando hubo que retomar las relaciones diplomáticas con la Francia libre e Italia, el visto bueno del Departamento de Estado estaría presente en las fuentes primarias revisadas (ACMRE, 1944a).

Nelson Rockefeller, nuevo subsecretario de Estado de los Estados Unidos de América visitó Venezuela en noviembre de 1944, acompañado de un grupo de expertos. Su intención era revisar el sistema de salubridad y el suministro de alimentos, además de los programas de información, para el logro de una mayor inserción de los sectores económicos estadounidenses en el entramado económico, social y político venezolano. La Guerra Mundial estaba en su etapa culminante y, aunque los actores involucrados no lo sabían, preveían un nuevo escenario político y económico en Latinoamérica de la postguerra. Es decir, los sectores comerciales estaban buscando garantizar el espacio vital norteamericano en Venezuela.

La diplomacia de Venezuela conocía las aspiraciones aliadas de formar una organización internacional que superara los errores de la Liga de Naciones realizando serias observaciones a la Conferencia de Dumbarton Oaks ${ }^{18}$ de noviembre de 1944. En este sentido, los problemas de la guerra y la paz son

18 Esta Conferencia fue el primer paso importante para cumplir uno de los apartados de la Declaración de la Conferencia de Moscú en 1943, donde se reconocía la necesidad de crear tras la guerra una organización que sustituyera la Sociedad de las Naciones. 
tratados por Venezuela en la Conferencia Interamericana sobre dicha temática a inicios de 1945 con la tutela del Departamento de Estado (MRE, 1945). A pesar de la solidaridad demostrada, Venezuela estuvo sola cuando formalizó su reclamo por el fusilamiento del Monseñor Montes de Oca por autoridades alemanas (ACMRE, 1944b).

En el contexto de la constitución de la Organización de Naciones Unidas y la Conferencia de San Francisco, el embajador Diógenes Escalante remitió al canciller Parra Pérez sus comentarios referentes al texto final, muy parecidos a las opiniones de senadores republicanos norteamericanos (ACMRE, 1945a), aspecto que evidenció la proximidad de los razonamientos de la diplomacia venezolana y estadounidense. Venezuela se hace presente en la fundación de la Organización de Naciones Unidas en San Francisco a través de una comisión en la que participaron el canciller Parra Pérez, el Doctor Gustavo Herrera, Ministro de Fomento, y el Doctor Alfredo Machado Hernández, director del Banco Central de Venezuela (ACMRE, 1945b).

Un elemento que fraguó ciertas diferencias con los Estados Unidos y las potencias aliadas vencedoras fue el concepto del "veto" que poseían las potencias vencedoras contra las decisiones pacíficas de las demás naciones (ACMRE, 1945c). Los debates de la Conferencia y las reuniones de los plenipotenciarios se detuvieron el 6 y el 9 de agosto de 1945 cuando el Enola Gay, un bombardero estadounidense arrojara las bombas atómicas sobre las ciudades de Hiroshima y Nagasaki. La Segunda Guerra Mundial había terminado y el mundo se preparaba para el estallido de la paz.

\section{Referencias bibliográficas}

Argyle, C. (1991). Cronología de la II Guerra Mundial. Registro ilustrado día por día 1939/1945. Colombia: Educar Cultural Recreativa. Cuarta edición.

\section{Fuentes primarias}

\section{Archivos del Ministerio de Relaciones Exteriores (ACMRE)}

ACMRE (1913). Resolución del Ministro de Relaciones Exteriores que designa a Caracciolo Parra Pérez y Henrique Gil Fortul agregados de la Legación de Venezuela en París, signada con el número 331 de fecha 22 de febrero de 1913.

ACMRE (1914). Resolución del Ministerio de Relaciones Exteriores publicada en Gaceta Oficial no. 12.266 .

ACMRE (1926). Resolución del Ministro de Relaciones Exteriores que designa a Caracciolo Parra Pérez Ministro Plenipotenciario ante el gobierno italiano.

ACMRE (1941a). Dirección General. Nota confidencial del Doctor Parra Pérez sobre la defensa nacional. Caracas, 18 de junio de 1941. Expediente no. 2.

ACMRE (1941b). Dirección General. Colombia. Nota de la Embajada de Venezuela en Bogotá, Caracas, 8 de diciembre de 1941. Expediente no. 34.
La dinámica de las relaciones diplomáticas entre Venezuela y los Estados Unidos durante el gobierno del general Isaías Medina Angarita (1941-1945)

Luis Manuel Marcano Salazar 
Dossier América Latina: Venezuela
ACMRE (1941c). Dirección General. Cuba. Nota del canciller Caracciolo Parra Pérez al Ministro de Estado José Manuel Cortina de Cuba, Caracas, 9 de diciembre de 1941. Expediente no. 11 .

ACMRE (1941d). Dirección General del despacho. Colombia. Nota de la Cancillería a todas las Embajadas número 702. Expediente no. 30.

ACMRE (1941e). Nota de la Cancillería a la Embajada de Venezuela en Washington. 10 de diciembre de 1941, Brasil. Expediente no. 18.

ACMRE (1941f). Nota confidencial a la Legación de Venezuela en Roma. Caracas 12 de diciembre de 1941. Expediente no. 20.

ACMRE (1941g). Dirección General. Colombia 1941. Nota de la cancillería firmada por el Canciller Parra Pérez.16 de diciembre de 1941. Expediente no. 34.

ACMRE (1941h). Dirección General. Estados Unidos. Nota de la Cancillería de Venezuela a la Embajada de Venezuela en Washington. 30 de diciembre de 1941. Expediente no. 10.

ACMRE (1941i). Dirección General, país, España. Caracas, 29 de diciembre de 1941. Expediente no. 65 .

ACMRE (1941j). Dirección General. Colombia. 1941 nota de la cancillería que comunica al señor Summer Wells la incautación de cargueros italianos y alemanes en puertos venezolanos. Expediente s/n.

ACMRE (1941k). Dirección de política. Expediente 10. Documento 2.

ACMRE (1942a). Dirección General. Estados Unidos. Nota de la cancillería que comunica al embajador Escalante. Expediente no. 19.

ACMRE (1942b). Dirección General. Estados Unidos. Nota de la cancillería. Expediente no. 19 .

ACMRE (1942c). Dirección General. Colombia. Caracas, 9 de enero de 1942. Expediente no. 202.

ACMRE (1943a). Nota del Canciller Parra Pérez sobre la aplicación de medidas sobre listas negras. Dirección General. Brasil. Caracas, 16 de enero de 1943. Expediente no. 3.

ACMRE (1943b). Dirección General de Política Económica. Estados Unidos. Aplicación de Lista Negra en Venezuela. Caracas 23 de julio de 1943. Pieza no. 20.

ACMRE (1944a). Dirección General. Estados Unidos. Canciller Parra Pérez a EmbavenezWashington. Venezuela es enteramente solidaria al pronto restablecimiento de relaciones diplomáticas con Italia y Francia. Caracas, 29 de septiembre de 1944. Expediente no. 54.

ACMRE (1944b). Dirección de Política. Sección relaciones otros Estados. Expediente no. 102, p. 1

ACMRE (1945a). Dirección de política Internacional. Conferencia de San Francisco. Expediente no. 102, p. 4

ACMRE (1945b). Dirección General. Conferencia de San Francisco, 1945. Expediente no. 16.

ACMRE (1945c). Dirección de Política Internacional. Estados Unidos, Expediente no. 102.

Archivo de Miraflores (1941a). Secretaria de la Presidencia. Despacho del presidente. Telegrama enviado por el cónsul de Maracaibo al presidente Isaías Medina Angarita. Diciembre 9 de 1941.

Archivo de Miraflores (1941b). Secretaria de la Presidencia. Despacho del presidente. Diciembre 9 de 1941. Documento 15, carpeta 1. 
Ministerio de Relaciones Exteriores (MRE). Introducción a la Memoria, Caracas, 1940 1941-1942-1943-1944

Ministerio de Relaciones Exteriores (MRE). Venezuela y las Conferencias Panamericanas 1928/1954. Tomo II.

\section{Archivos de la Fundación para el Rescate del Acervo Documental Venezolano (FUNRES)}

Archivo Diplomático FUNRES (1940). Comunicación de fecha 17 de mayo de 1940. Documentos Americanos 1940-1944. Caracas: Biblioteca Nacional.

Archivo Diplomático FUNRES (1945). Documentos Americanos 1940-1944. Caracas: Biblioteca Nacional.

\section{Archivos Nacionales de Washington (NARA), Estados Unidos de Norte América 1941-1944}

NARA (1940). Comunicación emitida por el embajador de los Estados Unidos de América en Caracas, Frank Corrigan, de fecha 30 de abril de 1940. Documentos del Departamento de Estado. Archivo numérico 6943/5970, rollo 23.

NARA (1941). Comunicación emitida por el embajador de los Estados Unidos de América en Caracas, Corrigan, de fecha 30 de abril de 1941 dirigida al Secretario de Estado norteamericano. Documentos del Departamento de Estado. Archivo numérico 7567/ 8563, rollo 67.

\section{Fuente videográfica}

Bolívar Films (1992). Isaías Medina Angarita, Soldado de la Libertad. Documental sobre el gobierno de Isaías Medina Angarita. Discurso de Medina Angarita ante el Congreso de los Estados Unidos de América. Trascripción del autor. Visto en febrero de 2011.

\section{La dinámica de las relaciones diplomáticas entre Venezuela y los Estados Unidos durante el gobierno del general Isaías Medina Angarita (1941-1945)}

Luis Manuel Marcano Salazar 